Article

\title{
Investigation on Possibility of Waste Vegetable Oil Rejuvenating Aged Asphalt
}

\author{
Cao Xinxin ${ }^{1}$, Cao Xuejuan ${ }^{2, *}$, Tang Boming ${ }^{1,2}$, Wang Yuanyuan ${ }^{2}$ and Li Xiaolong ${ }^{2}$ \\ 1 School of Civil Engineering, Chongqing Jiaotong University, Chongqing 400074, China; \\ caoxinxin1988@foxmail.com (C.X.); tangbm6@163.com (T.B.) \\ 2 School of Materials Science and Engineering, Chongqing Jiaotong University, Chongqing 400074, China; \\ wyy1005@seu.edu.cn (W.Y.); lixiaolong0715@163.com (L.X.) \\ * Correspondence: caoxuejuan79@foxmail.com
}

Received: 22 April 2018; Accepted: 8 May 2018; Published: 11 May 2018

\begin{abstract}
In order to guarantee the service performance of recycling asphalt mixture with reclaimed asphalt pavement (RAP), asphalt rejuvenator shall be added. In the last five years, vegetable oil-based rejuvenators have received more and more attention due to their green and regenerative advantages. The object of this paper is to investigate the feasibility of rejuvenating aged asphalt by a kind of waste vegetable oil (W-oil). The effect of $\mathrm{W}$-oil on the performance of aged asphalt is characterized by a safety property test, aging property test, and pavement performance tests; the pavement performance tests included traditional tests and a rheological test. The results show that both the safety property and aging property of rejuvenated asphalt with $\mathrm{W}$-oil meet the specification requirements. According to the results of traditional performance indexes (i.e., penetration, soften point, and ductility), the pavement performance of rejuvenated asphalt can be recovered to the level of virgin asphalt. According to the results of performance indices obtained from the rheological test, the optimum dosage of $\mathrm{W}$-oil is determined to be $13.4 \mathrm{wt} \%$. Compared with virgin asphalt, the rutting property of rejuvenated asphalt is equivalent to that of virgin asphalt, and the workability is slightly poorer; however, the fatigue property and low temperature property have been significantly enhanced. $\mathrm{W}$-oil cannot only improve the pavement performance of aged asphalt, it can also guarantee good safety property and aging property. Therefore, $\mathrm{W}$-oil is of great potential to serve as an asphalt rejuvenator for rejuvenating aged asphalt.
\end{abstract}

Keywords: asphalt; rejuvenator; vegetable oil; pavement performance; traditional indexes; rheological indexes

\section{Introduction}

Recycling reclaimed asphalt pavement (RAP) has good economic and environmental benefits. In the case of a RAP dosage between $20-50 \%$, it can save the cost of construction by $14-34 \%$ [1], which can reduce the exploitation of non-renewable resources (e.g., stone and asphalt), and thus reduce energy consumption and pollution emission in mining and transportation [2]. However, when RAP dosage goes beyond $20 \%$, there is a gradual increase in the deterioration of pavement's fatigue cracking and low-temperature cracking [3], and the compact of asphalt mixture will also be damaged [4]. To solve the shortcomings of rejuvenated asphalt mixture with a high dosage of RAP, it often requires the addition of a rejuvenator [5]. Rejuvenators mainly include vegetable oil and petroleum-based extracted oil [6], among which vegetable oil has attracted much attention in recent years because of its renewable advantage.

In 2012, Hallizza Asli et al. [7], on the basis of the indicators (e.g., penetration, soften point, and viscosity), pointed out that there was no clear difference in the performance between rejuvenated 
asphalt with fring vegetable oil and virgin asphalt. In 2014, Chen Meizhu et al. [8,9] utilized frying vegetable oil to rejuvenate aged asphalt, and the study showed that frying soybean oil significantly improved the fatigue property and low temperature anti-cracking property of aged asphalt, but the ductility was not effectively improved, and high temperature performance became poorer with the increase of frying soybean oil. In 2016, Wan et al. [10] added methyl alcohol into frying vegetable oil and made a chemical modification under alkalis catalysis, and it was found that the asphalt that was rejuvenated by the modified frying vegetable oil could achieve a better rutting resistance. In 2017, Zhang et al. [11] appraised the effects of vegetable oil with different deep-frying times on the rheological performance of aged asphalt, and the study exhibited that vegetable oil of a higher aging degree could result in a higher viscosity and a better rutting resistance. In summary, frying vegetable oil can restore the penetration of aged asphalt, as well as improve the fatigue property and low-temperature anti-cracking property of aged asphalt; however, high-temperature rutting resistance will become poorer. Vegetable oil, after modification or further aging, can reduce the damage of vegetable oil on rutting resistance. Herein, in this study, it was considered to apply highly aged waste vegetable oil of high viscosity to rejuvenate aged asphalt. The waste vegetable oil is sourced from the byproduct after the extraction of fatty acid from vegetable oil, and this byproduct is named as $\mathrm{W}$-oil in this paper. W-oil is the byproduct obtained by eight-hour distillation at $300-400{ }^{\circ} \mathrm{C}$ after the acidification of vegetable oil. W-oil has a higher viscosity and deeper aging degree than that of frying vegetable oil. The output of W-oil is large in China, and the main treatment measure taken at present is combustion, which has not been effectively utilized. Therefore, it is necessary to explore the application of $\mathrm{W}$-oil in rejuvenating asphalt.

\section{Objective and Experimental Plan}

This paper is aimed at observing the effects of $\mathrm{W}$-oil on the performance of aged asphalt and analyzing the potential of $\mathrm{W}$-oil as an asphalt rejuvenator. It can not only provide an environment-friendly way to treat $\mathrm{W}$-oil, it can also become a substitute for non-renewable petroleum-based asphalt rejuvenator, which will promote the development of sustainable pavement construction.

The test plan is shown in Figure 1. First, aged asphalt is obtained by two steps: virgin asphalt is aged by rolling thin film oven test (RTFOT), then put the aged residue of RTFOT into a pressurized aging vessel (PAV) for further aging to get aged asphalt. Second, $5 \%, 10 \%, 15 \%$, and $20 \% \mathrm{~W}$-oil is added into the aged asphalt to prepare rejuvenated asphalt. Third, the safety property, aging property and pavement performance of virgin asphalt, aged asphalt, and rejuvenated asphalt is analyzed. Pavement performance is characterized by two indexes, namely, the traditional indexes and rheological indexes. The flash point test is to characterize the asphalt's safety, and the RTFOT test is to characterize its aging property. In the traditional indexes, the penetration test, soften point test, and ductility test are used to characterize asphalt pavement performance. Corresponding to the traditional indexes for measuring asphalt pavement performance, superpave proposed the test methods based on rheology theory, so that the rheological index can be directly correlated to the field pavement performance. The viscosity test is used to characterize the high-temperature workability, the multiple stress creep recovery (MSCR) test is used to characterize the rutting property, the time sweep (TS) test is used to characterize the medium-temperature fatigue property, and the bending beam rheometer (BBR) test is to characterize low temperature property. 


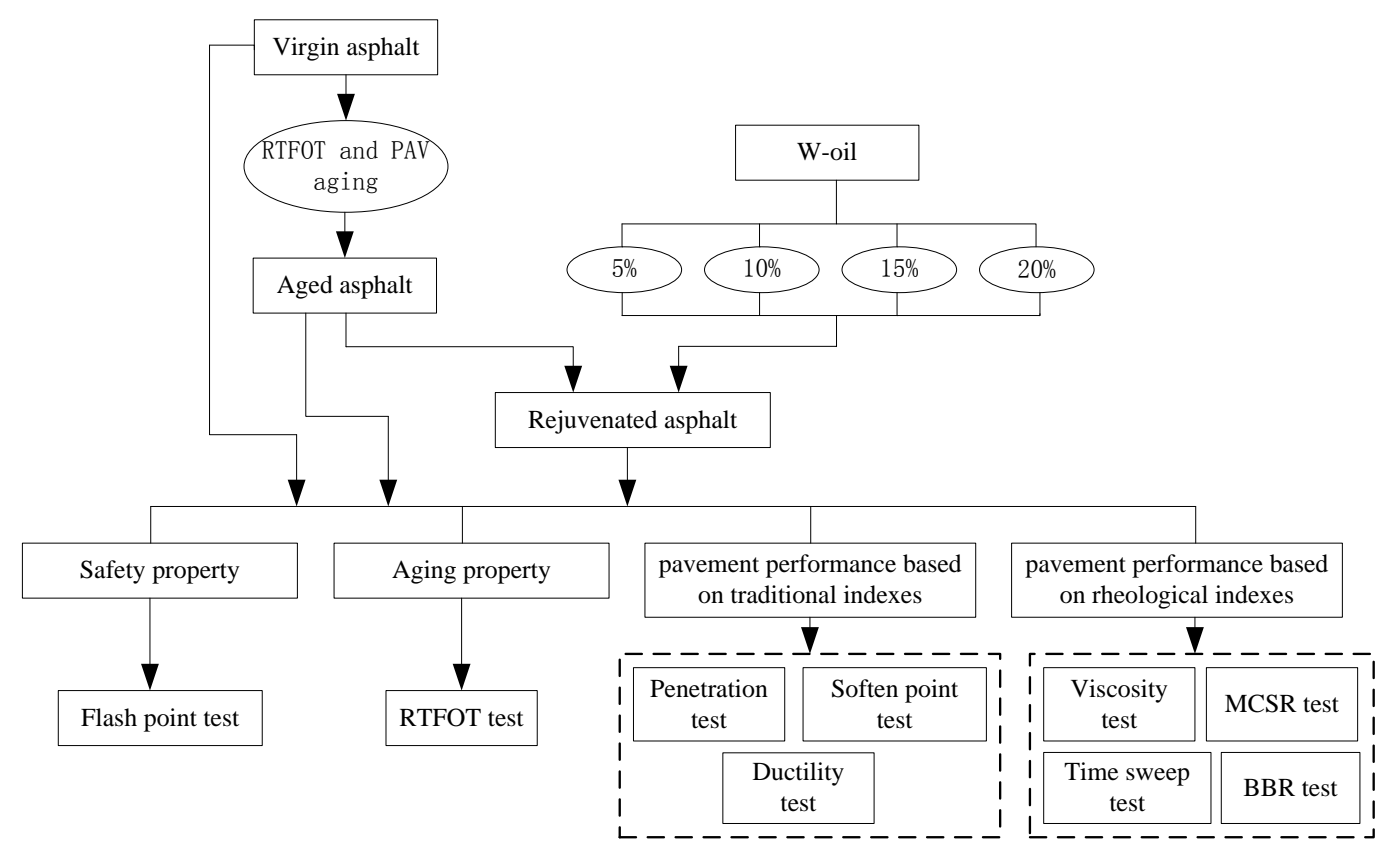

Figure 1. The Test Plan.

\section{Materials and Testing Methods}

\subsection{Materials}

\subsubsection{W-Oil}

W-oil is the byproduct after the extraction of fatty acid from vegetable oil, as shown in Figure 2. At present, the annual output of W-oil is approx. 900,000 tons, and the main treatment measure for waste oil is combustion, which produces a pungent odor and greenhouse gas, which pollutes the environment. The typical physical properties of W-oil are shown in Table 1. As shown in Table 1, the low viscosity of $\mathrm{W}$-oil, as $286.7 \mathrm{mPa} \cdot \mathrm{S}$, means that at $60^{\circ} \mathrm{C}$, it can soften aged asphalt effectively. In general, the higher the molecular weight, the less volatile it is. The number-average molecular weight of W-oil is 1067 Daltons, so W-oil is expected to have a good anti-volatile performance in construction as a rejuvenator. Fourier transform infrared spectroscopy (FTIR) is a method of determining the chemical functional groups within a medium. The chemical functional groups are groups of atoms that are responsible for different reactions within a compound [12]. In Figure 3, a comparison of infrared spectrogram is made between virgin asphalt and $\mathrm{W}$-oil. The major differences in the composition of functional groups include: (1) W-oil has a stronger absorption peak at $1150 \mathrm{~cm}^{-1}$ and $1700 \mathrm{~cm}^{-1}$, while virgin asphalt basically has no absorption peak, implying that $\mathrm{W}$-oil contains a large number of ester bonds; (2) Virgin asphalt shows absorption peaks at $800 \mathrm{~cm}^{-1}$ and $1580 \mathrm{~cm}^{-1}$, where W-oil has no absorption peak, which demonstrates that W-oil does not contain benzene. Therefore, W-oil does not contain strong carcinogen-polycyclic aromatic hydrocarbon (PAH), and the use of W-oil as a rejuvenator can reduce the harm to the construction workers. 


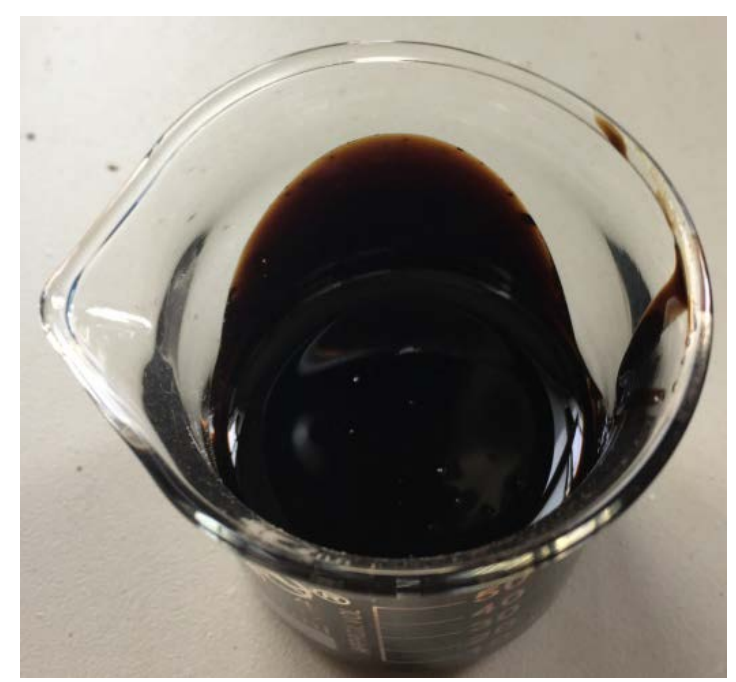

Figure 2. W-oil.

Table 1. Physical Properties of W-oil.

\begin{tabular}{ccccc}
\hline $\begin{array}{c}\text { Physical } \\
\text { Properties }\end{array}$ & Density $/\left(\mathrm{g} / \mathrm{cm}^{3}\right)$ & Color & $\begin{array}{c}\text { Viscosity at } \\
\mathbf{6 0}{ }^{\circ} \mathrm{C} / \mathrm{mPa} \cdot S\end{array}$ & $\begin{array}{c}\text { Number-Average Molecular } \\
\text { Weight Mn/Daltons }\end{array}$ \\
\cline { 2 - 5 } & 0.966 & Nigger-brown & 286.7 & 1067 \\
\hline
\end{tabular}

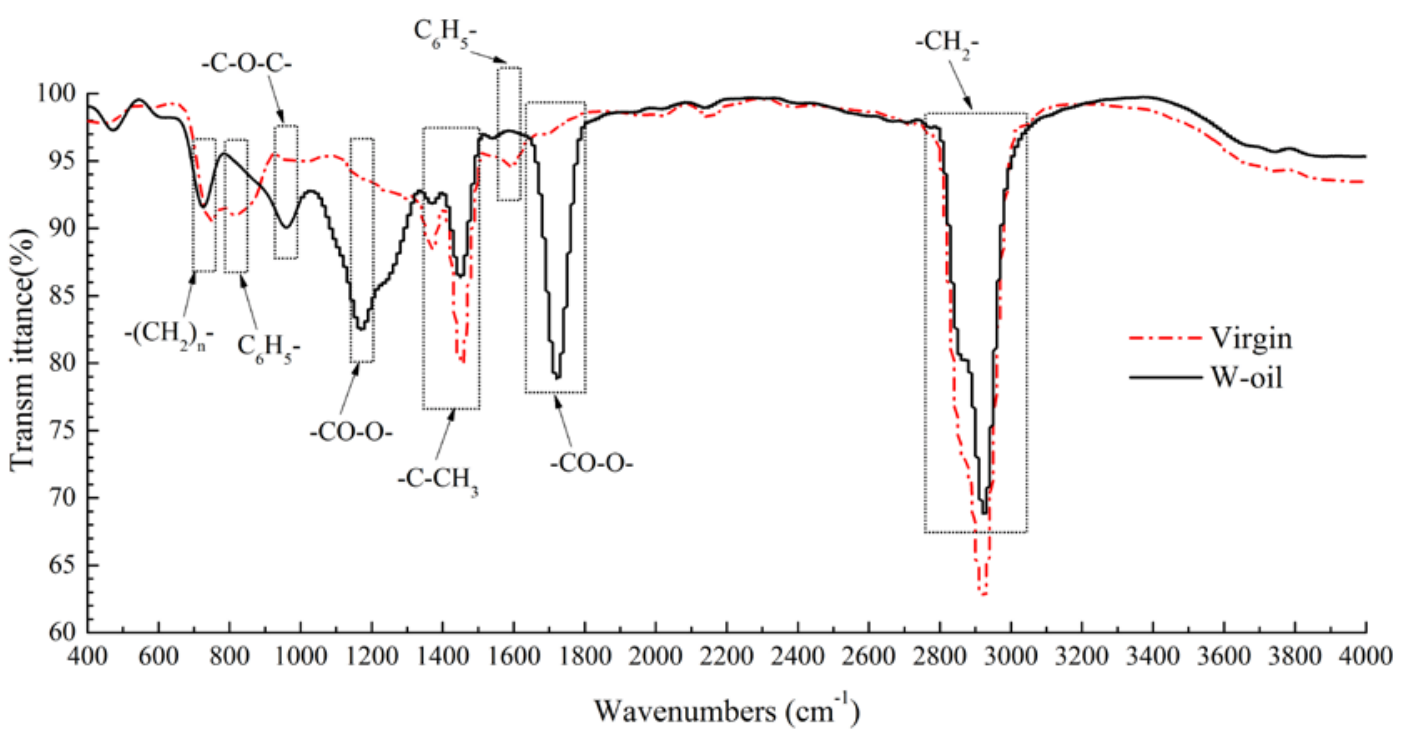

Figure 3. Fourier transform infrared (FTIR) Spectra of W-oil and Virgin Asphalt.

\subsubsection{Asphalt}

(1) Virgin asphalt and aged asphalt

PEN70 asphalt is used as the virgin asphalt. Aged asphalt is prepared by aging PEN70 asphalt in the laboratory. Asphalt aging includes short-term aging and long-term aging. Short-term aging is simulated by the rolling thin film oven test (RTFOT), long-term aging is simulated by the accelerated aging test of asphalt in a pressurized aging vessel (PAV). The PAV test is conducted at the temperature $100{ }^{\circ} \mathrm{C}$ for $20 \mathrm{~h}$ to simulate asphalt field aging for six to eight years. For the specific experimental method, refer to ASTM D 2872 [13] and ASTM D6521 [14]. The technical indicators for virgin asphalt and aged asphalt are as shown in Table 2. 
Table 2. Physical Index of Virgin and Aged Asphalt.

\begin{tabular}{cccc}
\hline Index & Penetration $\left(\mathbf{2 5}{ }^{\circ} \mathbf{C}, \mathbf{5 ~ s}\right) / \mathbf{0 . 1} \mathbf{~ m m}$ & Ductility $\left(5^{\circ} \mathbf{C}\right) / \mathbf{c m}$ & Soften Point $/{ }^{\circ} \mathbf{C}$ \\
\hline Virgin asphalt & 64.6 & 11.1 & 49.2 \\
Aged asphalt & 25.2 & 0.8 & 65.6 \\
\hline
\end{tabular}

(2) W-oil rejuvenated asphalt

W-oil is mixed into the aged asphalt at proportions (by weight) of $5 \%, 10 \%, 15 \%$, and $20 \%$ at a recovering temperature of $135{ }^{\circ} \mathrm{C}$ in the stirrer at a speed of $2000 \mathrm{RPM}$ for $15 \mathrm{~min}$. Virgin asphalt, aged asphalt, and 5\%,10\%, 15\%, and 20\% W-oil rejuvenated asphalt are named as Virgin, 0\%WRA, 5\%WRA, $10 \%$ WRA, $15 \%$ WRA, and 20\%WRA, respectively.

\subsection{Testing Methods}

\subsubsection{Flash Point Test}

The flash point reflects the safety of asphalt in the process of mixing at a high temperature. The higher the flash point, the more safe the asphalt. The flash point test is applied to characterize the safety of virgin, aged, and rejuvenated asphalt. As shown in Figure 4, the rate of temperature rise is set between $5-6{ }^{\circ} \mathrm{C} / \mathrm{min}$ during the last $28^{\circ} \mathrm{C}$ before the flash point. The test flame is passed across the center of the test cup. For the observed flash point, the temperature is recorded at the time the test flame causes a distinct flash in the interior of the test cup. For the details of the test, refer to ASTM D 92-12b [15].

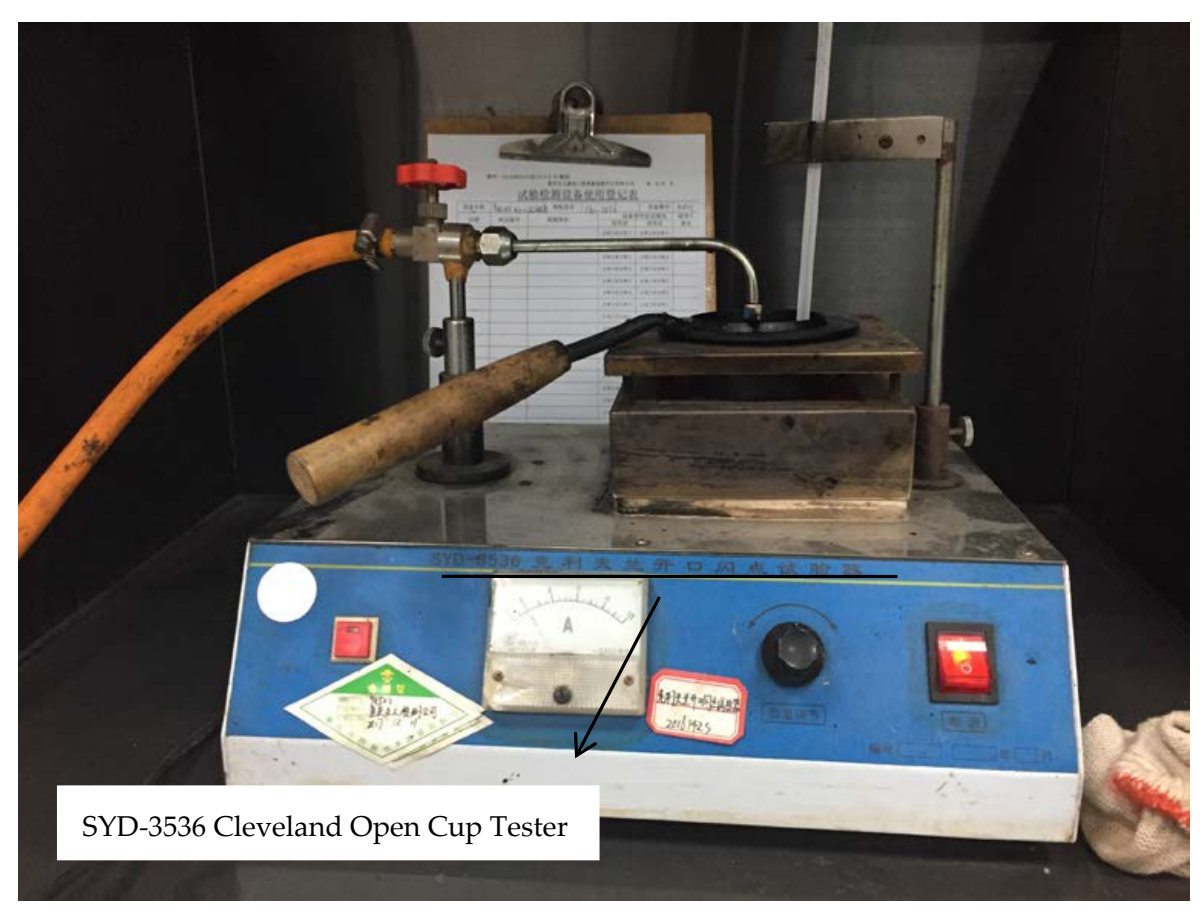

Figure 4. The Cleveland Open Cup Tester.

\subsubsection{Rolling Thin Film Oven Test (RTFOT)}

RTFOT simulates the short-term aging in mixing process. The smaller mass loss that the aged asphalt has, the better the aging property is. The RTFOT test is applied to characterizing the safety of virgin, aged, and rejuvenated asphalt. As shown in Figure 5, asphalt samples are conditioned in a rolling thin film oven at $163{ }^{\circ} \mathrm{C}$ for $85 \mathrm{~min}$. For the details of the test, refer to ASTM D2872 [13]. 


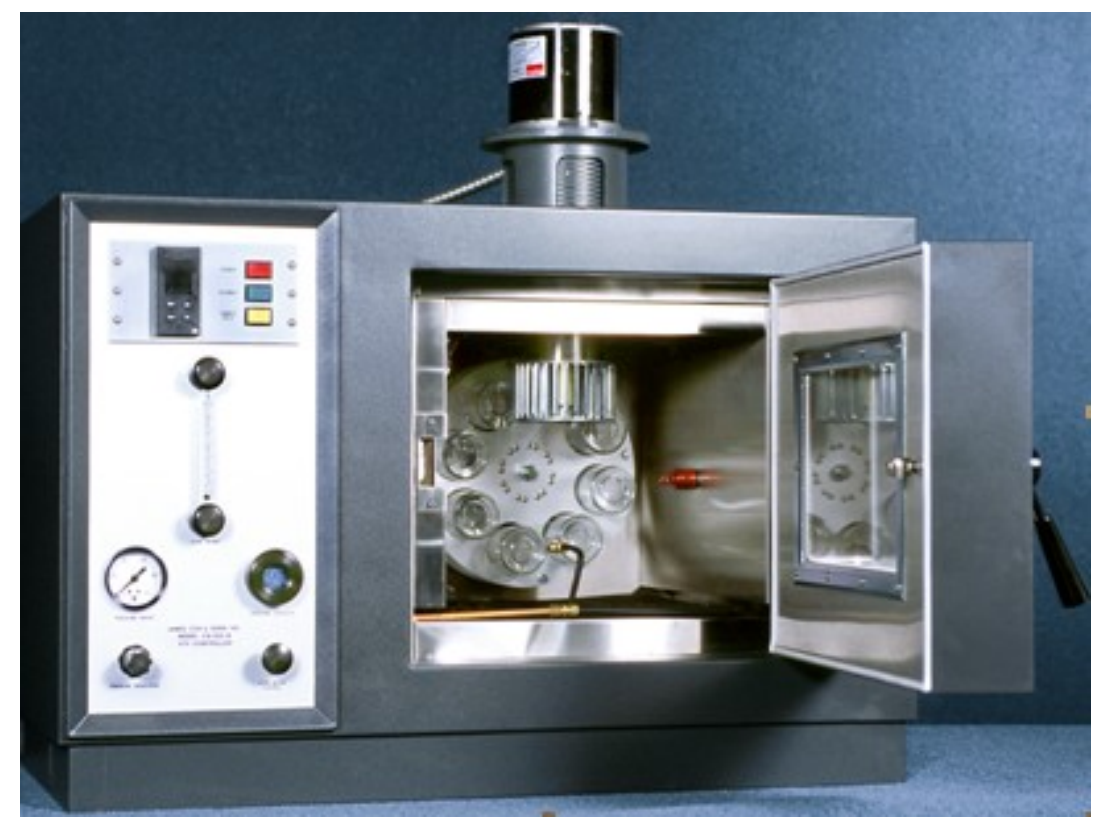

Figure 5. The Rolling Thin Film Oven.

\subsubsection{Physical Tests}

(1) Penetration test

Penetration is a grading index of asphalt. For example, if the penetration range is 60-80, the asphalt is defined as PEN70. As shown in Figure 6, a container filled with an asphalt sample is stored in a $25^{\circ} \mathrm{C}$ water bath for $90 \mathrm{~min}$, and then penetrated by a needle weighted $100 \mathrm{~g}$; the penetration depth is measured as a penetration in the unit of $0.1 \mathrm{~mm}$. For the details of penetration test, refer to ASTM D5 [16].

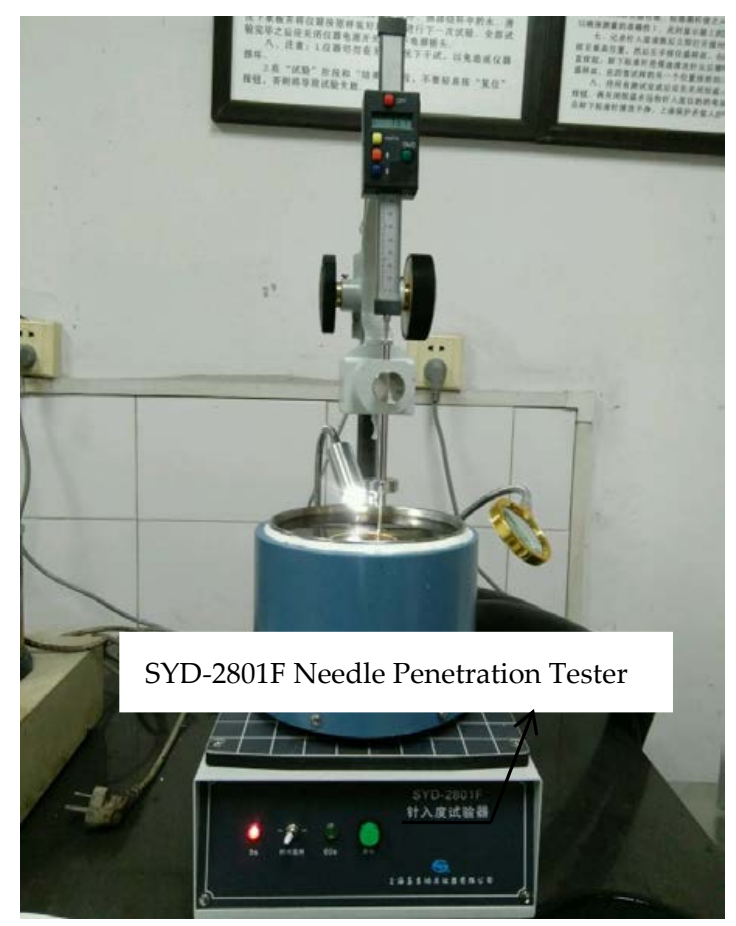

Figure 6. The Needle Penetration Tester. 


\section{(2) Soften point test}

The soften point reflects the high-temperature stability of asphalt. The higher the soften point, the better the anti-rutting performance of the asphalt. As shown in Figure 7, two steel balls are placed on the horizontal disks of an asphalt sample contained in vertically supported metal rings. The assembly is heated in a water bath at $5{ }^{\circ} \mathrm{C} / \mathrm{min}$. The softening point was recorded as the average temperature at which the two disks softened enough to allow each ball, enveloped in asphalt, to fall a distance of $25 \mathrm{~mm}$ (1.0 in). For the details of soften point test, refer to ASTM D36 [17].

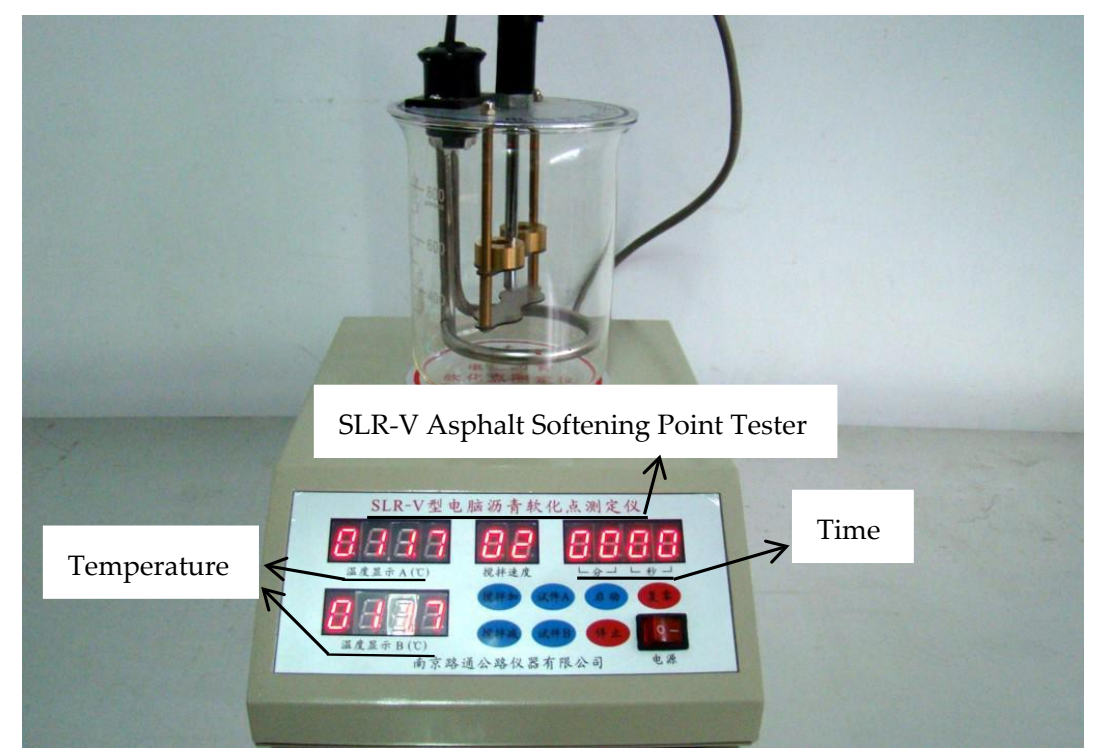

Figure 7. Softening Point Tester.

(3) Ductility test

Ductility reflects the ductility of asphalt. The higher the ductility, the better performance the asphalt has. The ductility test is used to measure the stretching length of a standard asphalt sample before breaking under standard testing condition $\left(1 \mathrm{~cm} / \mathrm{min}\right.$ stretching speed at $\left.5{ }^{\circ} \mathrm{C}\right)$, as shown in Figure 8. For the details of the ductility test, refer to ASTM D113 [18].

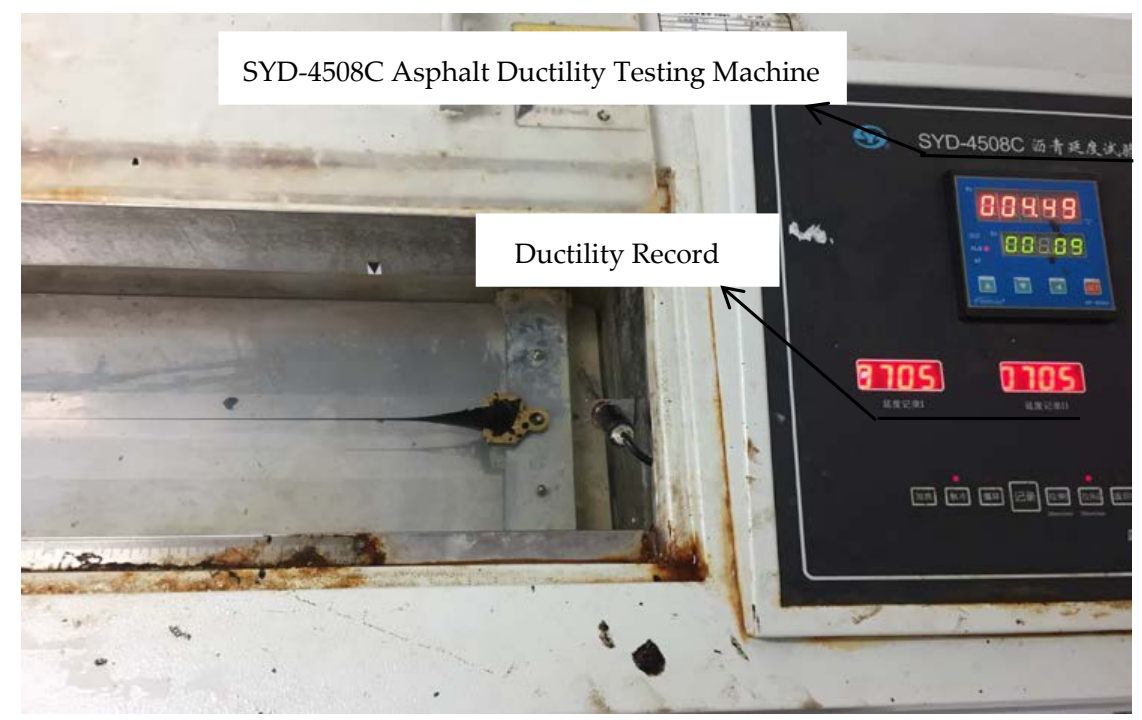

Figure 8. The Ductility Testing Machine. 


\subsubsection{Rheological Tests}

(1) Viscosity test

In the mixing and compacting process of asphalt mixture, the viscosity of asphalt shall be kept within a certain range. Excessive viscosity will cause insufficient compacting of asphalt mixture, and too low viscosity will result in a waste of energy. The workability of asphalt can be characterized by a viscosity test. The viscosity of specimen is measured respectively at $120^{\circ} \mathrm{C}, 135^{\circ} \mathrm{C}, 150{ }^{\circ} \mathrm{C}, 165^{\circ} \mathrm{C}$, and $180^{\circ} \mathrm{C}$ in this study. For the details of the test, refer to ASTM D4402 [19].

(2) Multiple Stress Creep Recovery (MSCR) test

In the Standard Specification for Performance Classification of Asphalt binder (AASHTO:M320), rutting factor $\left(\left|G^{*}\right| / \sin \delta\right)$ is adopted as the high-temperature performance indicator of asphalt. Rutting factor can predict the high temperature performance of unmodified asphalt well, but there is still a dispute on its applicability for modified asphalt [20,21]. An MSCR test can reflect the nonlinear rheological response of modified asphalt under a large stress, and it has been confirmed that non-recoverable creep compliance $\left(\mathrm{J}_{\mathrm{nr}}\right)$ has a good correlativity with the rutting property of modified asphalt [22]. Both the physical and chemical properties change dramatically after asphalt aging, and W-oil rejuvenated asphalt is regarded as modified asphalt. To predict the high-temperature performance of W-oil rejuvenated asphalt more accurately, a $\mathrm{Jnr}_{\mathrm{nr}}$ indicator achieved by the MSCR test is adopted in this paper.

The MSCR test applies an AR 2000 dynamic shear rheometer (DSR): an 8-mm plate is applied for the specimens of $0 \%$ WRA and 5\%WRA, and the gap between the parallel plates is set to be $2 \mathrm{~mm}$; a $25 \mathrm{~mm}$ plate is applied for the specimens of Virgin, 10\%WRA, 15\%WRA and 20\%WRA, and the gap between the rotor's parallel plates is set at $1 \mathrm{~mm}$. The testing temperature for specimens is $60^{\circ} \mathrm{C}$, and the loading frequency is $10 \mathrm{rad} / \mathrm{s}$. Specimens are loaded respectively under a stress of $0.1 \mathrm{kPa}$ and $3.2 \mathrm{kPa}$; the loading process is to load for $1 \mathrm{~s}$, then recover for $9 \mathrm{~s}$. Each stress includes 10 cycles of loading and recovering.

(3) Time Sweep (TS) test

Superpave research proposes the fatigue factor $\left(\left|G^{*}\right| \times \sin \delta\right)$, which is similar to the asphalt rutting factor and takes it as a control index of asphalt fatigue resistance. However, the fatigue factor cannot characterize the fatigue damage characteristics, and it has poor correlation with the asphalt mixture's fatigue property. Asphalt fatigue life, which is obtained from the time sweep test, can reflect the fatigue resistance of the corresponding asphalt mixture [23]. The number of loading cycles $\left(\mathrm{N}_{\mathrm{f} 50}\right)$ in the case of a complex modulus decreased to $50 \%$ is taken as the index for judging the asphalt fatigue [16]. The time sweep test is carried out to characterize the fatigue property of virgin, aged, and rejuvenated asphalt.

The TS test applies AR 2000 DSR, which is the same instrument as in the MSCR test. An 8-mm plate is applied for $0 \% \mathrm{WRA}$ and $5 \% \mathrm{WRA}$, and the gap between the parallel plates is set at $2 \mathrm{~mm}$; a 25-mm plate is applied for Virgin, 10\%WRA, 15\%WRA, and 20\%WRA, and the gap between the parallel plates is set $1 \mathrm{~mm}$. A $5 \%$ strain control mode is applied for all of the specimens, the loading frequency is $10 \mathrm{rad} / \mathrm{s}$, and the testing temperature is $20^{\circ} \mathrm{C}$.

(4) Bending Beam Rheometer (BBR) test

The model of the testing instrument is TE-BBR. The flexural creep stiffness or flexural creep compliance, as determined from this test, describes the low-temperature stress-strain time response of the asphalt binder at the test temperature within the range of linear viscoelastic response. Creep stiffness $(\mathrm{S})$ and creep rate $(\mathrm{m})$ are used to assess the low temperature anti-cracking property in this paper. For the testing method, refer to ASTM D 6648 "Standard Test Method for Determining the Flexural Creep Stiffness of Asphalt Binder Using the Bending Beam Rheometer (BBR)". 


\section{Results and Discussion}

\subsection{Safety Property}

Figure 9 shows the flash points of virgin asphalt, aged asphalt, and rejuvenated asphalt with different dosages of W-oil. According to Figure 9, it can be seen that the flash point increases slightly after asphalt aging, and decreases after the addition of W-oil, which demonstrates that W-oil is harmful to the safety of aged asphalt. As noted in ASTM D92-16b, the flash point can indicate the possible presence of highly volatile and flammable materials in a relatively nonvolatile or nonflammable material. The highly volatile and flammable materials are hazardous in asphalt mixing and compacting at high temperature, which may lead to fire and explosion. The flash point of aged asphalt and W-oil are $320{ }^{\circ} \mathrm{C}$ and $262{ }^{\circ} \mathrm{C}$, respectively, which indicate that $\mathrm{W}$-oil contains more highly volatile and flammable materials. As the dosage of W-oil in aged asphalt increases, the dosage of highly volatile and flammable materials in rejuvenated asphalt also increases. Therefore, W-oil is harmful to the safety of aged asphalt. Although the addition of $\mathrm{W}$-oil decreases the flash point of aged asphalt, the flash point of $20 \%$ WRA, $268^{\circ} \mathrm{C}$, is still far higher than $230{ }^{\circ} \mathrm{C}$, which is the flash point specified in the Superpave Binder Requirement (AASHTO M 320), and demonstrates that W-oil rejuvenated asphalt has good safety in construction.

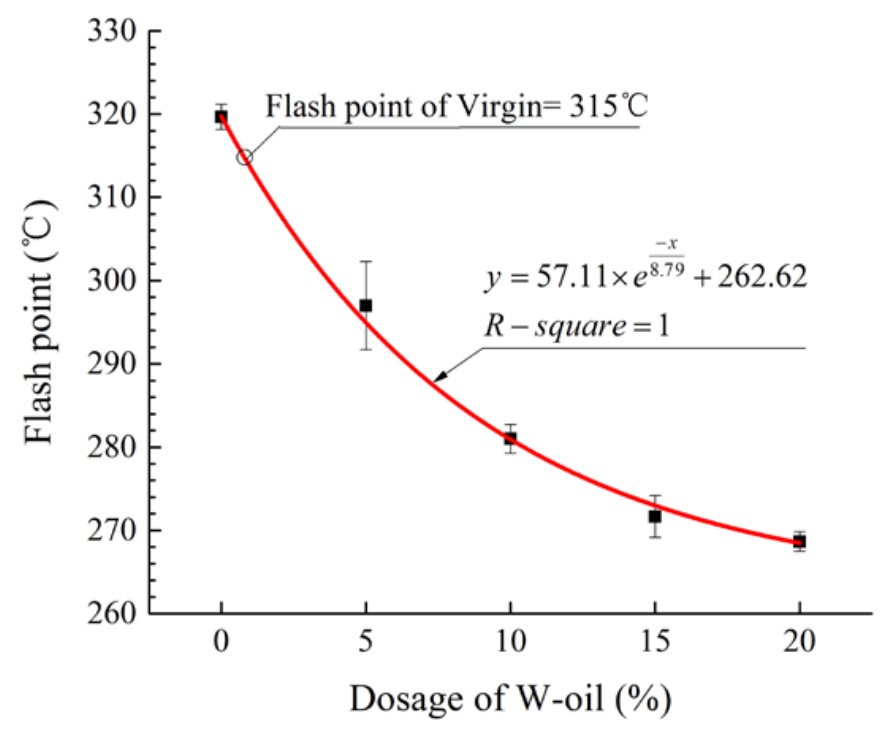

Figure 9. Flash Points of Virgin, Aged, and Rejuvenated Asphalt.

\subsection{Aging Property}

Figure 10 shows the mass loss of virgin asphalt, aged asphalt, and rejuvenated asphalt with different dosages of W-oil. According to Figure 10, it can be seen that the mass loss decreases after asphalt aging, which is due to the volatilization of light components in the aging process. The mass loss increases after the addition of W-oil, because $\mathrm{W}$-oil contains light components with low boiling points. The mass loss of $\mathrm{W}$-oil in rejuvenated asphalt is smaller than that of virgin asphalt, which implies that W-oil cannot fully replenish the light components in virgin asphalt that are lost in the aging process [24]. The mass loss presents a linear increase with the dosage of $\mathrm{W}$-oil. When the dosage of W-oil is $20 \%$, the mass loss is $0.27 \%$, which is far smaller than the mass loss of $1 \%$ that is specified in the Superpave Binder Requirement (AASHTO M 320). The smaller mass loss the asphalt has, the better its aging resistance is, so it demonstrates that rejuvenated asphalt has a better aging property. 


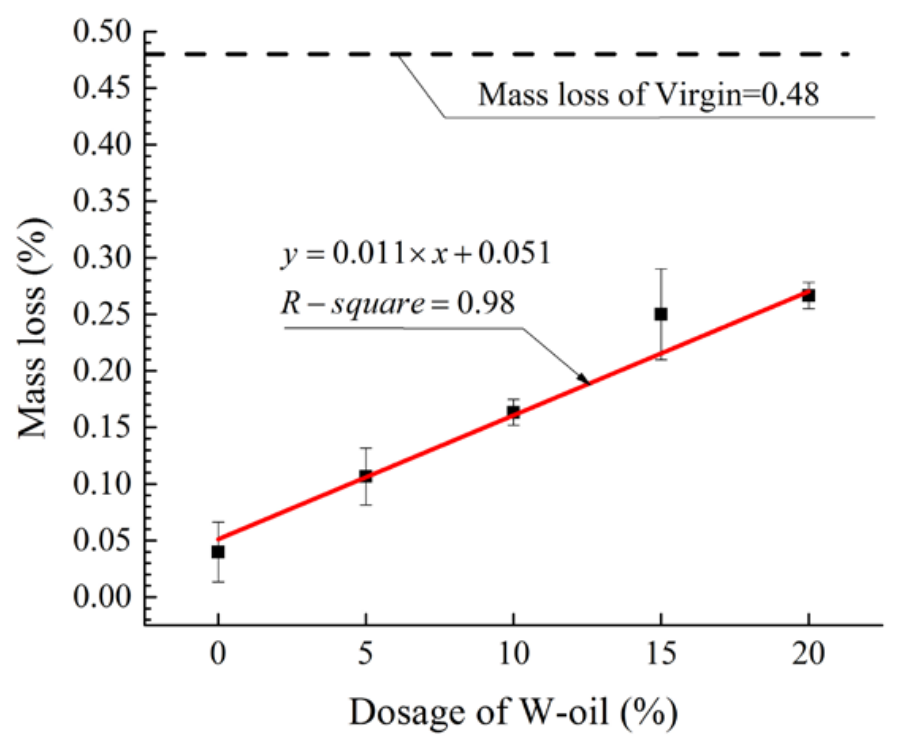

Figure 10. Mass Loss of Virgin, Aged, and Rejuvenated Asphalt.

\subsection{Pavement Performance Based on Physical Tests}

\subsubsection{Penetration}

Penetration is commonly used for grading. According to Figure 11, it can be seen that the penetration decreases after asphalt aging. As the dosage of $\mathrm{W}$-oil increases, the penetration of rejuvenated asphalt increases gradually, and the penetration of rejuvenated asphalt is well linear with the dosage of $\mathrm{W}$-oil. When the dosage of $\mathrm{W}$-oil is $9.5 \%$, the penetration of rejuvenated asphalt is recovered to the level of virgin asphalt.

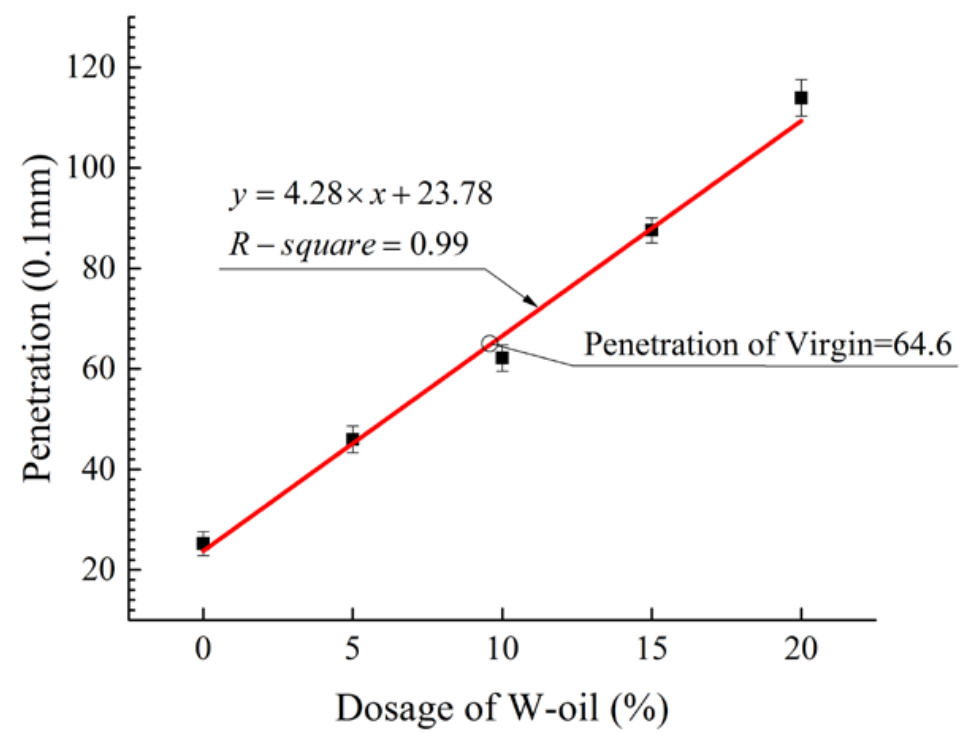

Figure 11. Penetration of Virgin, Aged, and Rejuvenated Asphalt.

\subsubsection{Soften Point}

The soften point can reflect the high temperature stability of asphalt. The higher the soften point is, the better the high temperature stability. According to Figure 12, it can be seen that the soften point rises after asphalt aging, and the aging effect improves the high temperature stability of asphalt. As dosage of $\mathrm{W}$-oil increases, the soften point of rejuvenated asphalt presents a linear decrease, which 
demonstrates that $\mathrm{W}$-oil reduces the high temperature stability of aged asphalt. When the dosage of $\mathrm{W}$-oil is $13 \%$, the soften point of rejuvenated asphalt is reduced to the level of virgin asphalt.

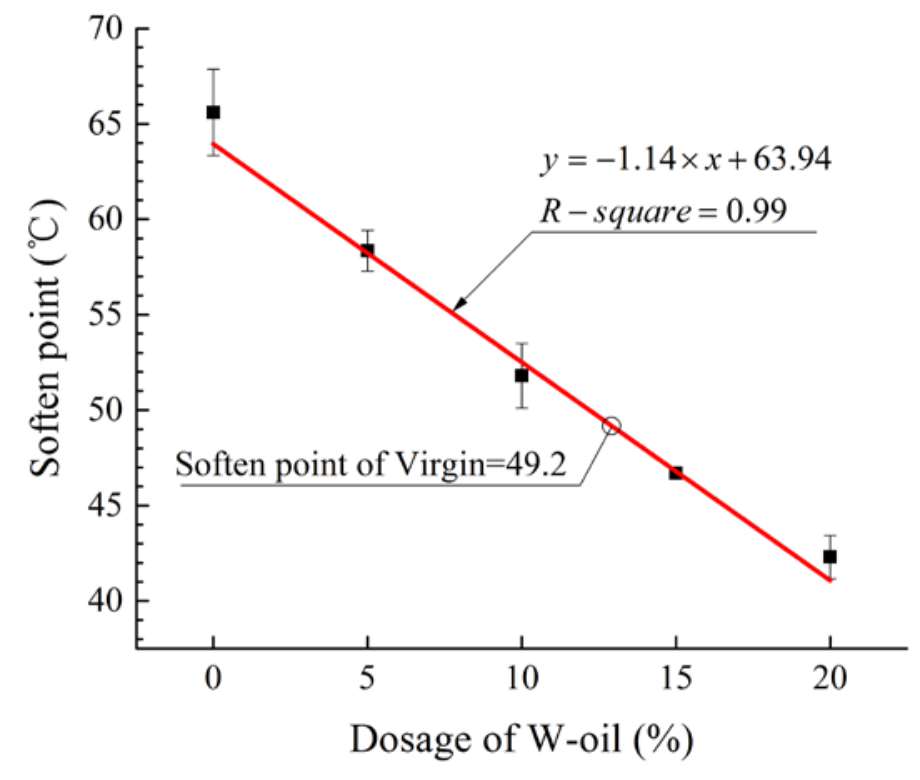

Figure 12. Soften Point of Virgin, Aged, and Rejuvenated Asphalt.

\subsubsection{Ductility}

The higher the ductility is, the better the pavement performance of the asphalt. According to Figure 13, it can be seen that the ductility decreases after asphalt aging, which demonstrates that an aging effect reduces the ductility of the asphalt. As the dosage of W-oil increases in the aged asphalt, the ductility of rejuvenated asphalt continuously increases, which implies that W-oil improves the ductility of aged asphalt. When the dosage of W-oil is $10 \%$, the ductility of rejuvenated asphalt is restored to the level of virgin asphalt.

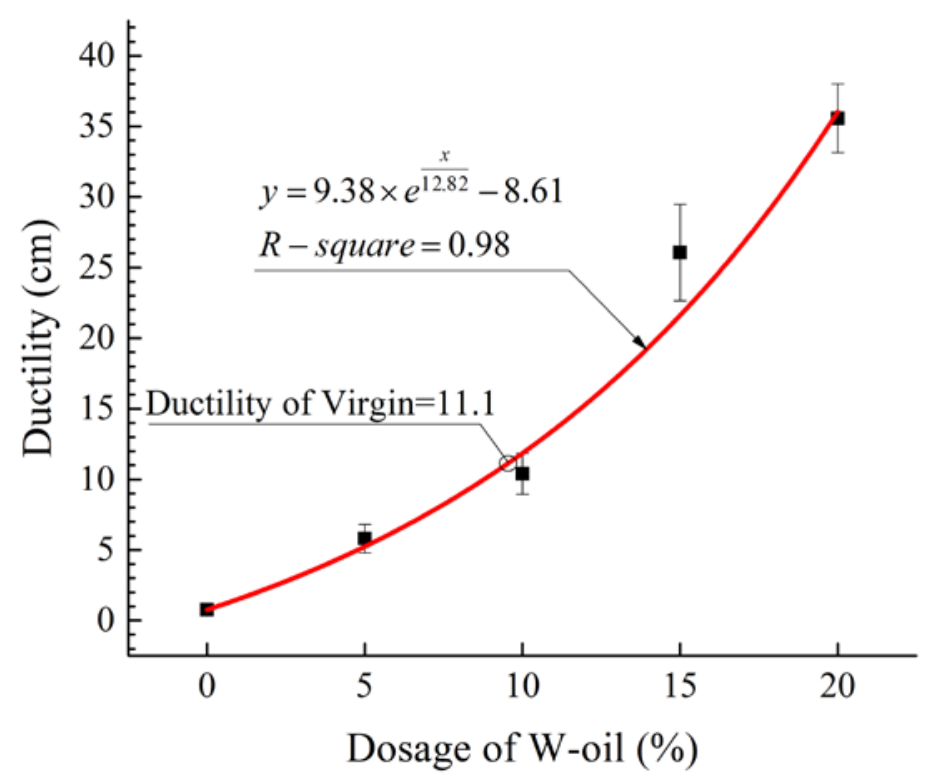

Figure 13. Ductility of Virgin, Aged, and Rejuvenated Asphalt. 


\subsection{Pavement Performance Based on Rheological Tests}

\subsubsection{Workability}

In order to guarantee the service performance of asphalt mixture, the viscosity of an asphalt binder shall be controlled within a certain range. In the Technical Specification for Construction of Highway Asphalt Pavement (JTG F40-2004), it is recommended that the optimum viscosity in the mixing and compacting process of asphalt binder to be $170 \mathrm{mPa} \cdot \mathrm{S}$ and $280 \mathrm{mPa} \cdot \mathrm{S}$, respectively. Figure 14 shows the viscosity-temperature curve of virgin asphalt, aged asphalt, and rejuvenated asphalt with different dosages of $\mathrm{W}$-oil at $120-180^{\circ} \mathrm{C}$. The line of recommending compacting viscosity and mixing viscosity are drawn at $280 \mathrm{mPa} \cdot \mathrm{S}$ and $170 \mathrm{mPa} \cdot \mathrm{S}$, respectively, in which the corresponding horizontal coordinate is the compacting and mixing temperature of the related asphalt. According to Figure 14, it can be seen that an increase of temperature makes the asphalt viscosity decrease, so the control on the optimum mixing and compacting viscosity of asphalt is realized by controlling the temperature. The lower the construction temperature, the less energy is required in the heating process, and the better the workability. The viscosity of virgin asphalt increases by an aging effect, and the mixing and compacting temperature of aged asphalt under the recommended mixing and compacting viscosity are $180^{\circ} \mathrm{C}$ and $168^{\circ} \mathrm{C}$, respectively. Both are increased by around $25^{\circ} \mathrm{C}$ in comparison with that of virgin asphalt, so aging effect lowers the workability of virgin asphalt. As the dosage of $\mathrm{W}$-oil in aged asphalt increases, the viscosity of rejuvenated asphalt reduces rapidly, which demonstrates that W-oil can improve the workability of aged asphalt. When the dosage of W-oil is $20 \%$, rejuvenated asphalt has a viscosity-temperature curve close to that of virgin asphalt, which demonstrates that $20 \%$ $\mathrm{W}$-oil shall be added to aged asphalt for restoring its workability to the virgin level. Viewing from the viscosity-temperature curves of $20 \% \mathrm{WRA}$ and virgin, the change in the viscosity of virgin asphalt is more sensitive to temperature, which demonstrates that the addition $\mathrm{W}$-oil can recover the viscosity of aged asphalt, but the temperature susceptibility cannot be recovered to the level of virgin asphalt.

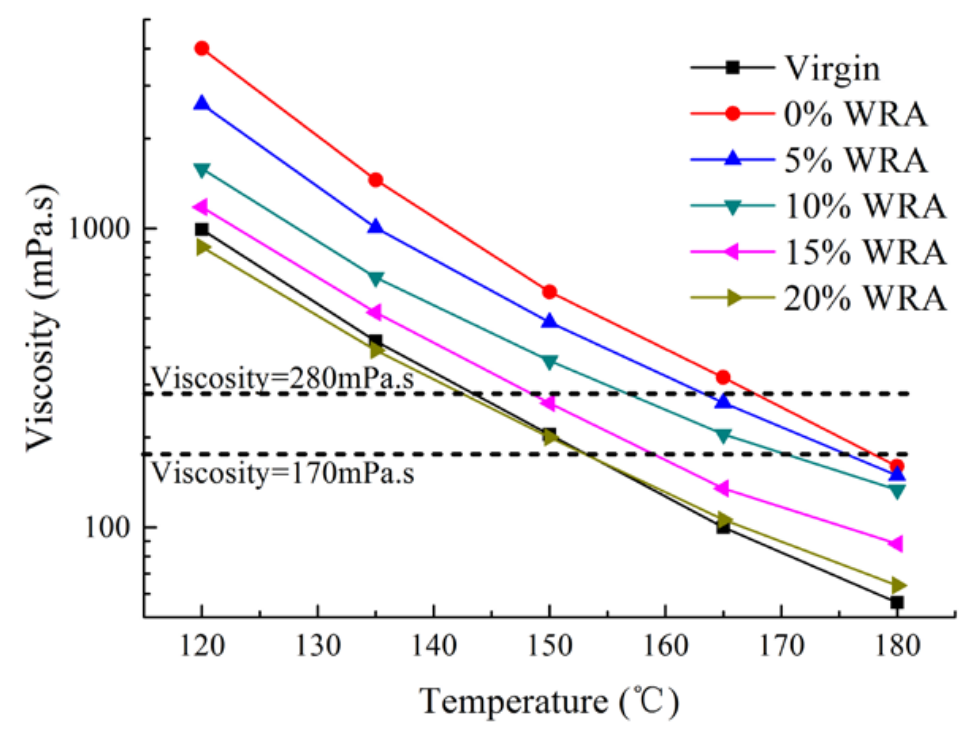

Figure 14. Viscosity-Temperature Curve of Virgin, Aged, and Rejuvenated Asphalt.

Figure 15 shows the mixing and compacting temperature of virgin asphalt, aged asphalt, and rejuvenated asphalt with different dosages of W-oil. It can be seen that, as the dosage of W-oil increases, the mixing and compacting temperature keep on declining. The construction temperature of rejuvenated asphalt presents a linear decrease with the addition of W-oil; it can be concluded that $\mathrm{W}$-oil improves the workability of aged asphalt. When the dosage of $\mathrm{W}$-oil is $20 \%$, the viscosity of rejuvenated asphalt is basically restored to the level of virgin asphalt. 


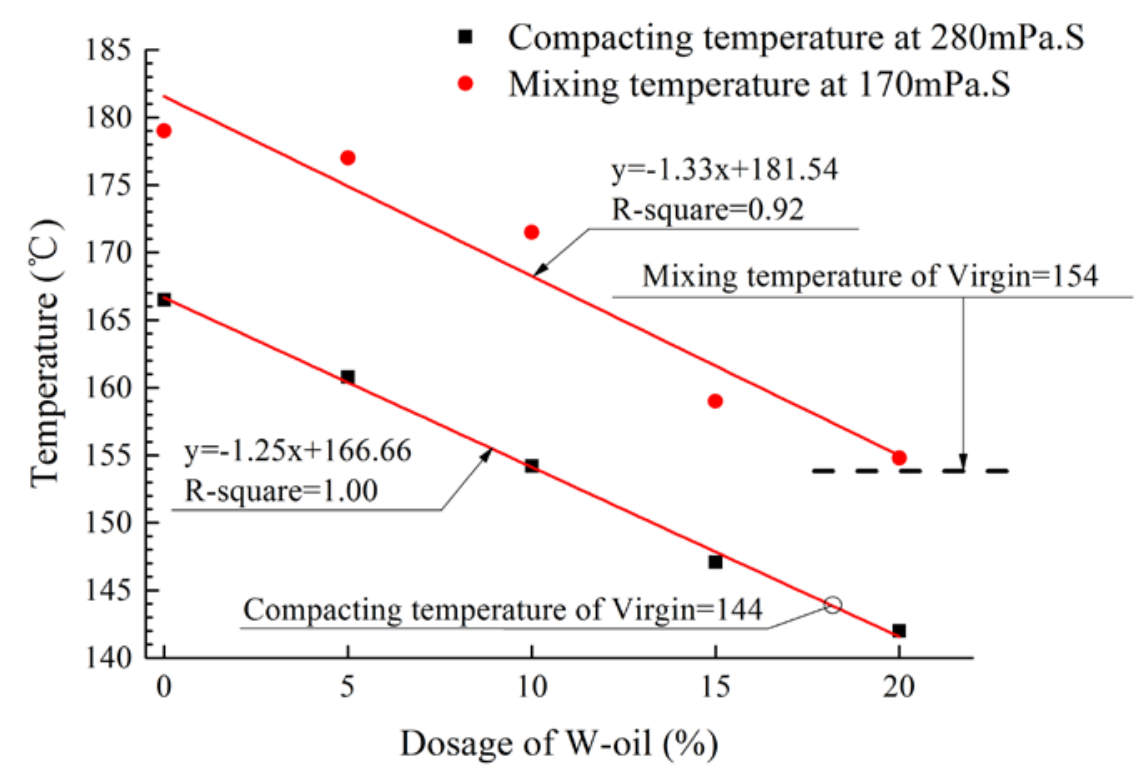

Figure 15. Mixing and Compacting Temperature of Virgin, Aged, and Rejuvenated Asphalt.

\subsubsection{Rutting Property}

Figure 16 shows the cumulative strain curve of specimens under two different stresses $(0.1 \mathrm{kPa}$ and $3.2 \mathrm{kPa}$ ). It can be seen that the cumulative deformation of $0 \% \mathrm{WRA}$ is the minimum. The cumulative deformation of virgin asphalt is far greater than that of $0 \% \mathrm{WRA}$, because the aging effect improves the non-deformability of asphalt. The addition of W-oil increases the cumulative deformation of aged asphalt. The higher dosage of $\mathrm{W}$-oil is, the higher the deformability of the rejuvenated asphalt. It is concluded that the deformation recovering capacity is improved by the aging effect, while the addition of W-oil lowers the deformation recovering capacity of aged asphalt. When the stress is $0.1 \mathrm{kPa}, 15 \%$ WRA has a cumulative deformation curve close to that of virgin asphalt, while in the case of $3.2 \mathrm{kPa}, 15 \%$ WRA has a cumulative deformation curve with a certain difference from that of virgin asphalt, which demonstrates that the trend of cumulative deformation under different stresses varies.

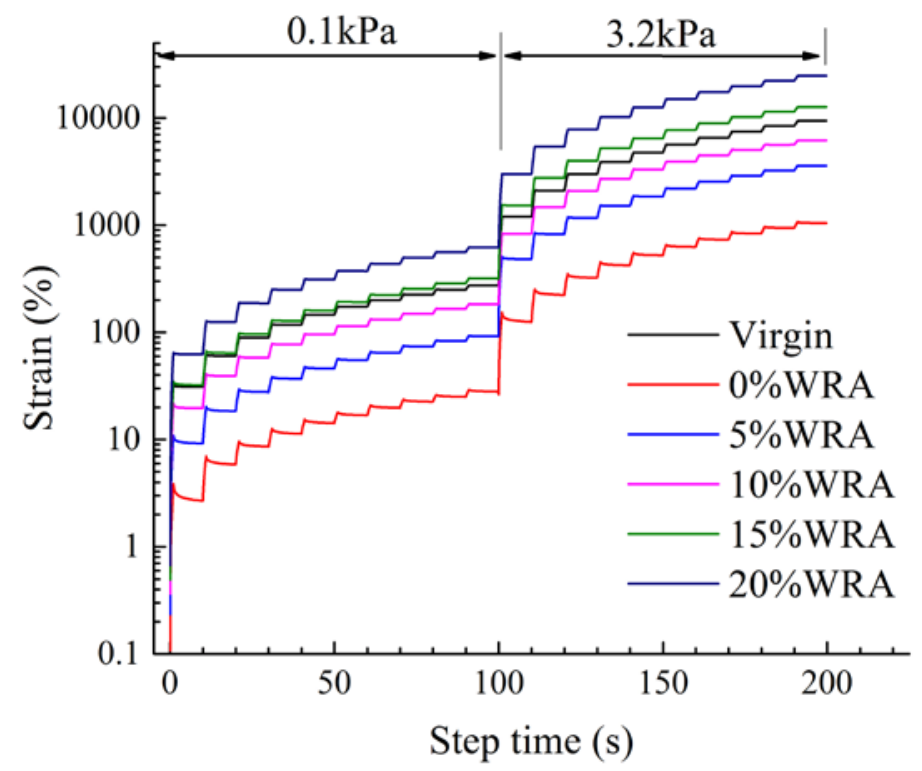

Figure 16. Multiple Stress Creep Recovery (MSCR) Curve of Virgin, Aged, and Rejuvenated Asphalt. 
Non-recoverable creep compliance $\left(J_{n r}\right)$ can characterize the anti-rutting property at high temperature well. The larger $J_{n r}$ is, the poorer the anti-rutting is; the smaller $J_{n r}$ is, the better the anti-rutting. The non-recoverable creep compliance $\left(J_{n r}\right)$ of each cycle under each stress can be calculated as Equation (1):

$$
J_{n r}=\frac{\gamma_{n r}}{\tau}
$$

where $\tau$ is the loading stress for each cycle, $\mathrm{kPa}$; and $\gamma_{n r}$ is the non-recoverable strain of the cycle.

According to Figure 17, it can be seen that the $J_{n r}$ of $0 \%$ WRA is far smaller than that for virgin asphalt; therefore, the aging effect improves the rutting resistance of asphalt. The larger the dosage of $\mathrm{W}$-oil is, the larger $J_{n r}$ value of the rejuvenated asphalt; it is concluded that W-oil lowers the rutting property of aged asphalt. There are differences in the $J_{n r}$ values of specimens under different stresses, but no obvious rules are found.

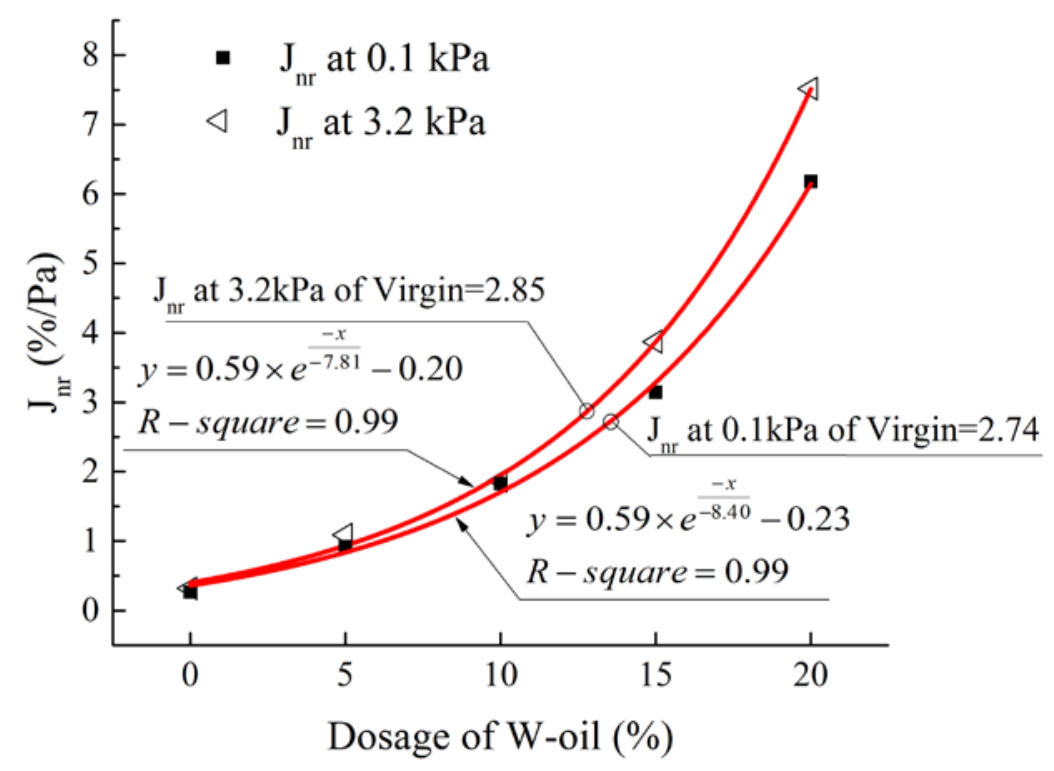

Figure 17. $J_{n r}$ of Virgin, Aged, and Rejuvenated Asphalt.

\subsubsection{Fatigue Property}

Figure 18 shows the impact of the number of loading cycles on the complex modulus of virgin, aged, and rejuvenated asphalt. It can be seen that as the number of loading cycles increases, the complex modulus decrease continuously, which demonstrates that loads are harmful to the structural strength of asphalt. The larger the dosage of W-oil is, the lower the initial modulus of rejuvenated asphalt. The declining trend of complex modulus becomes slower; thus, $\mathrm{W}$-oil improves the fatigue property of aged asphalt on the basis of reducing the initial modulus. However, as an asphalt binder for pavement, it shall not only consider the fatigue property, but also guarantee the high initial modulus. Therefore, the optimum dosage of $\mathrm{W}$-oil shall be controlled in order to ensure the high temperature and fatigue property of asphalt. Besides, the modulus curve of virgin asphalt is close to that of $10 \% \mathrm{WRA}$, so there is a close fatigue property between virgin asphalt and 10\%WRA.

$\mathrm{N}_{\mathrm{f} 50}$ is taken as the index for evaluating asphalt fatigue. Figure 19 shows the $\mathrm{N}_{\mathrm{f} 50}$ values of virgin asphalt, aged asphalt, and rejuvenated asphalt with different dosages of W-oil. It can be seen that, as the dosage of $\mathrm{W}$-oil increases, the fatigue life of rejuvenated asphalt increases exponentially. 


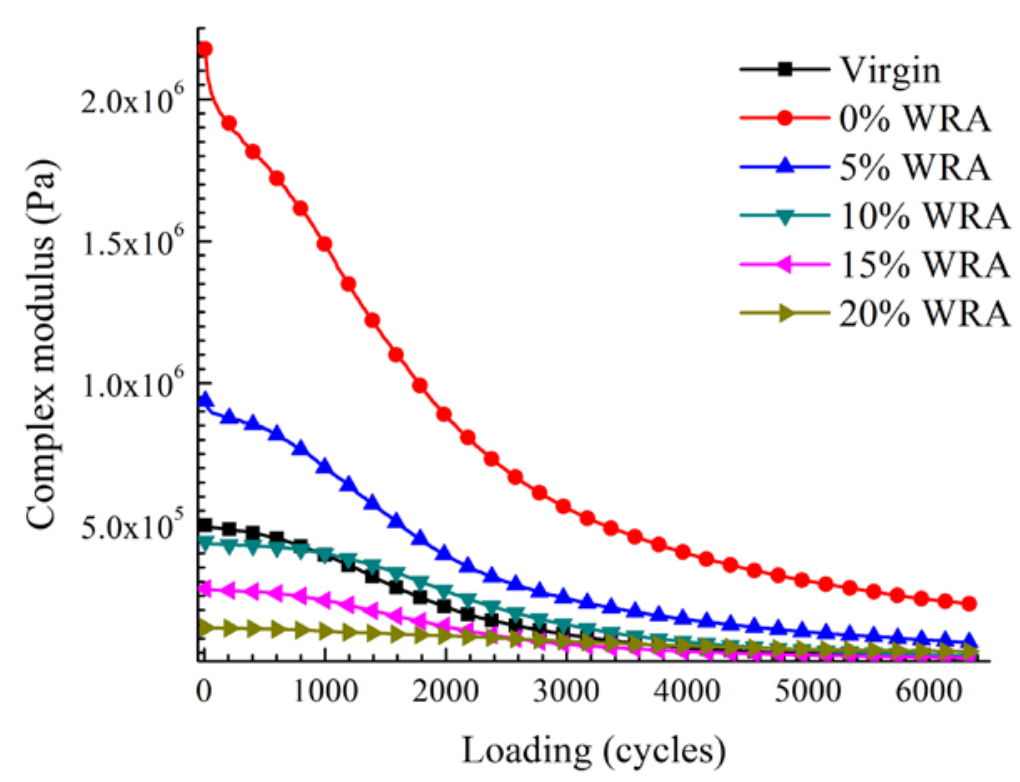

Figure 18. Change of Complex Modulus under Loading.

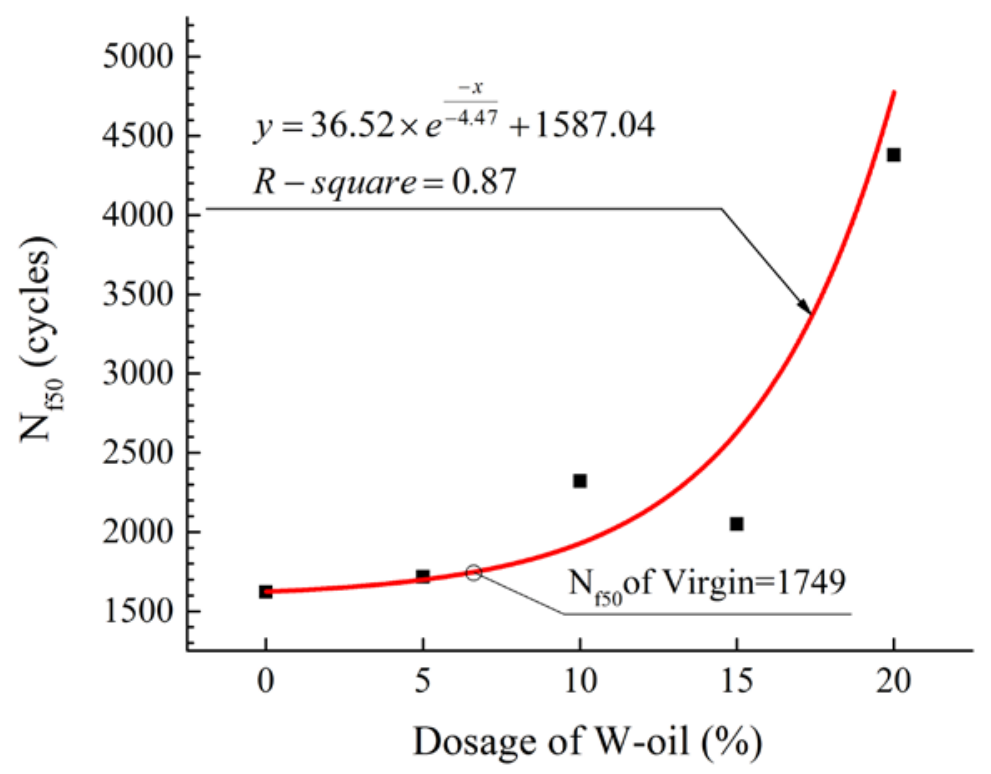

Figure 19. $\mathrm{N}_{\mathrm{f} 50}$ of Virgin, Aged, and Rejuvenated Asphalt.

\subsubsection{Low Temperature Property}

The creep stiffness $(\mathrm{S})$ and creep rate $(\mathrm{m})$ of virgin, aged, and rejuvenated asphalt at $-12{ }^{\circ} \mathrm{C}$ are shown in Figure 20. The creep stiffness significantly increases, and the creep rate significantly declines after aging, which demonstrates that the aging effect will make asphalt harden and easily crack at low temperature. With the addition of $\mathrm{W}$-oil, the creep stiffness of aged asphalt decreases, and the creep rate rises, which demonstrates that $\mathrm{W}$-oil improves the low temperature anti-cracking property of aged asphalt. When the dosage of W-oil is $20 \%$, the test fails to complete, because $20 \%$ WRA is too soft. The value of $S$ and $m$ in Figure 20 is set as 0 and 1, respectively. When the dosage of $W$-oil is $8 \%$ and $13 \%$, the $\mathrm{S}$ and $\mathrm{m}$ values of rejuvenated asphalt are recovered respective to the level of virgin asphalt, respectively, which demonstrates that the effect of W-oil on creep stiffness is larger than its effect on the creep rate. 


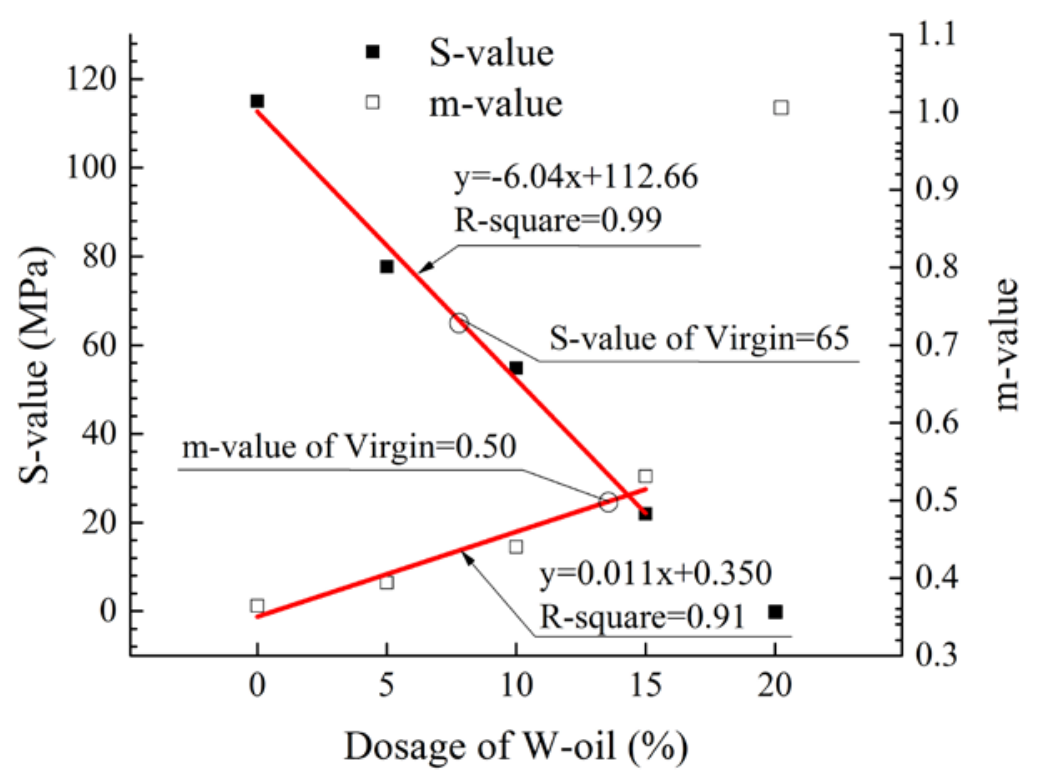

Figure 20. S and m Values of Virgin, Aged, and Rejuvenated Asphalt.

\subsection{Analyzing Possibility of W-Oil as Rejuvenator}

The pavement performance of asphalt becomes poor due to the aging effect, and the aim of adding rejuvenator is to restore the pavement performance of aged asphalt. First of all, the optimum dosage of $\mathrm{W}$-oil shall be determined. In this paper, the optimum dosage is determined by the rheological index, because the rheological index can be directly correlated to the field pavement performance. According to the test results of performance indices obtained from the rheological test, with the increasing dosage of $\mathrm{W}$-oil, the workability, fatigue property and low-temperature performance of rejuvenated asphalt are improved. However, the rutting resistance of rejuvenated asphalt is declining. The principles of determining the optimal dosage of $\mathrm{W}$-oil are: under the premise of ensuring the high-temperature performance of rejuvenated asphalt, improve the workability, fatigue property, and low-temperature performance of aged asphalt to the maximum. Taking the $J_{n r}$ value of rejuvenated asphalt no lower than that of virgin asphalt as the criteria, the calculated dosage, making $J_{n r}$ in the case of $3.2 \mathrm{kPa}$ and $0.1 \mathrm{kPa}$ restore to the level of virgin asphalt, is respectively $13.0 \%$ and $13.7 \%$, and the average value of $13.4 \%$ is taken as the optimum dosage of $\mathrm{W}$-oil.

The feasibility of the rejuvenator is usually evaluated by comparing the properties of virgin asphalt and rejuvenated asphalt. For carrying out a comparative analysis on the performance of $13.4 \% \mathrm{~W}$-oil rejuvenated asphalt and virgin asphalt, the safety, aging, and pavement performance indices of virgin and rejuvenated asphalt shall be processed for normalization, as shown in Figure 21. The optimum dosage of $\mathrm{W}$-oil is determined as $13.4 \%$, which is based on the same high-temperature stability as virgin asphalt. The safety of rejuvenated asphalt with $13.4 \% \mathrm{~W}$-oil is poorer than that of virgin asphalt, while the safety can still meet the specification requirements. The aging property is superior to that of virgin asphalt. The ductility is better than that of virgin asphalt. The workability is slightly poorer than virgin asphalt, and will be further improved. The fatigue life of rejuvenated asphalt is longer than that of virgin asphalt by approximately $33 \%$. The value $m$ of rejuvenated asphalt is close to that of virgin asphalt, but the value $\mathrm{S}$ is lower by $47 \%$ than virgin asphalt; therefore, the low-temperature property of rejuvenated asphalt is better than that of virgin asphalt. In summary, $\mathrm{W}$-oil can significantly improve the properties of aged asphalt, and it is of great potential to serve as an asphalt rejuvenator. 


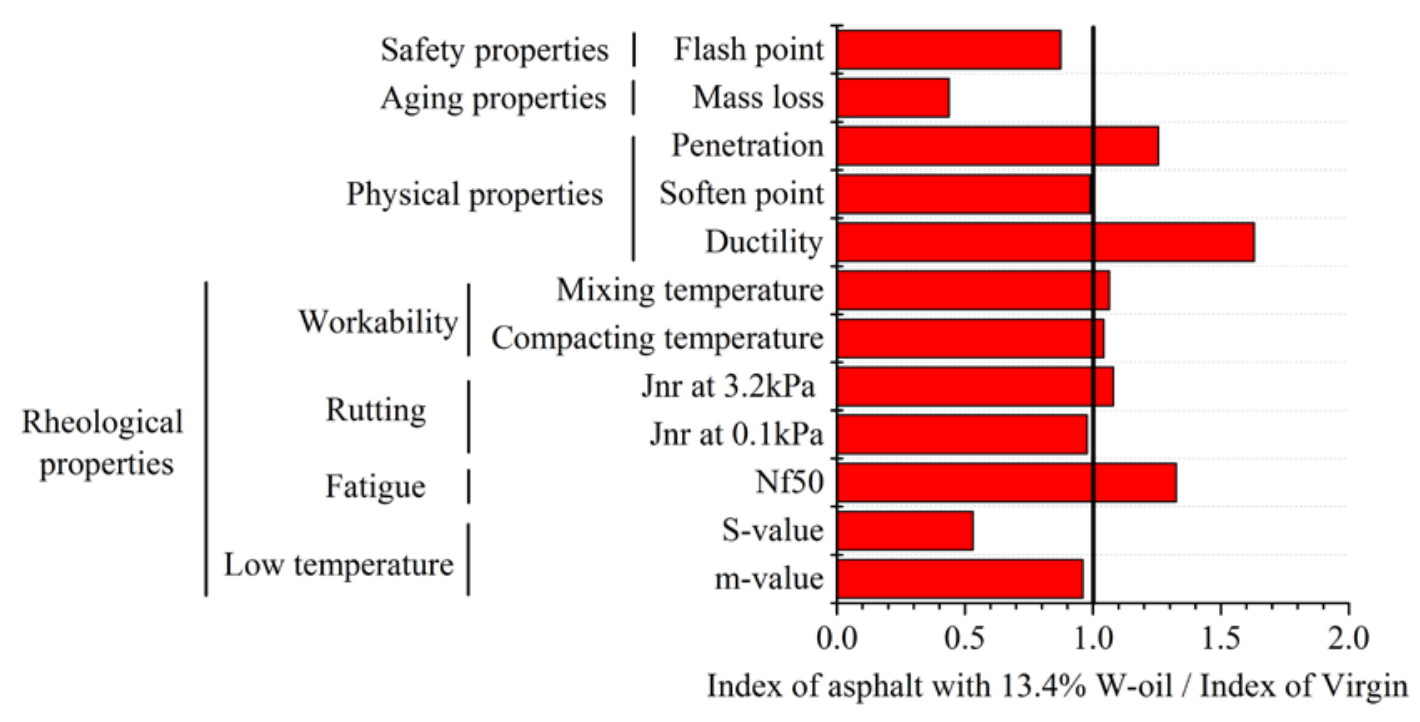

Figure 21. Ratio of Index of Virgin Asphalt and Rejuvenated Asphalt with 13.4\% W-oil.

\section{Conclusions}

Based on the experimental results from virgin, aged, and rejuvenated asphalt in terms of safety, aging, and traditional and rheological property tests, the following conclusions can be drawn:

(1) Both the safety and aging property of W-oil rejuvenated asphalt decrease while the dosage of $\mathrm{W}$-oil is increasing. When the dosage of $\mathrm{W}$-oil is smaller than $20 \%$, the flash point and mass loss of rejuvenated asphalt can still meet the specification requirements.

(2) As the dosage of $\mathrm{W}$-oil increases, the penetration and ductility of rejuvenated asphalt increase, while the soften point declines. W-oil can recover the penetration, soften point, and ductility of aged asphalt to the level of virgin asphalt.

(3) As the dosage of $\mathrm{W}$-oil increases, the workability of rejuvenated asphalt is improved, the fatigue life is extended, and the low-temperature property is improved, while the rutting resistance is reduced.

(4) Under the premise of the high-temperature performance of rejuvenated asphalt, the optimum dosage of W-oil is determined to be $13.4 \%$. The safety and aging property of rejuvenated asphalt can meet the specification requirements; the pavement performance basically recovers to the level of virgin asphalt.

(5) W-oil can improve the safety, aging, and pavement performance of aged asphalt. W-oil is of great potential to serve as asphalt rejuvenator, while the workability and rutting property are to be further improved.

Author Contributions: C.X., C.X. and T.B. conceived and designed the experiments; C. X. and L.X. performed the experiments; C.X. and C.X. analyzed the data; T.B. and W.Y. contributed reagents/materials/analysis tools; C.X. and W.Y. wrote the paper.

Acknowledgments: This work is supported by Chongqing Postgraduate Scientific Innovation Project (2017B0103) and Chongqing Traffic Science and Technology Project. The authors gratefully acknowledge their financial support.

Conflicts of Interest: The authors declare no conflict of interest.

\section{References}

1. Kandhal, P.S.; Mallick, R.B. Pavement Recycling Guidelines for State and Local Governments: Participant's Reference Book; Final Report; National Transportation Library: Washington, DC, USA, 1998.

2. Aurangzeb, Q.; Al-Qadi, I.L.; Ozer, H.; Yang, R. Hybrid life cycle assessment for asphalt mixtures with high RAP content. Resour. Conserv. Recycl. 2014, 83, 77-86. [CrossRef] 
3. He, G.P.; Wong, W.G. Effects of moisture on strength and permanent deformation of foamed asphalt mix incorporating RAP materials. Constr. Build. Mater. 2008, 22, 30-40. [CrossRef]

4. Mogawer, W.; Bennert, T.; Daniel, J.S.; Bonaquist, R.; Austerman, A.; Booshehrian, A. Performance characteristics of plant produced high RAP mixtures. Road Mater. Pavement Des. 2012, 13 (Suppl. 1), 183-208. [CrossRef]

5. Holden, D.A.; Strauss, J. HP-GPC characterization of rejuvenated aged CRM binders. J. Mater. Civ. Eng. 2007, 19, 515-522.

6. Zaumanis, M.; Mallick, R.B.; Frank, R. Evaluation of Rejuvenator's Effectiveness with Conventional Mix Testing for 100\% Reclaimed Asphalt Pavement Mixtures. Transp. Res. Rec. J. Transp. Res. Board. 2013, 28, 17-25. [CrossRef]

7. Asli, H.; Ahmadinia, E.; Zargar, M.; Karim, M.R. Investigation on physical properties of waste cooking oil-Rejuvenated bitumen binder. Constr. Build. Mater. 2012, 37, 398-405. [CrossRef]

8. Chen, M.; Xiao, F.; Putman, B.; Leng, B.; Wu, S. High temperature properties of rejuvenating recovered binder with rejuvenator, waste cooking and cotton seed oils. Constr. Build. Mater. 2014, 59, 10-16. [CrossRef]

9. Chen, M.; Leng, B.; Wu, S.; Sang, Y. Physical, chemical and rheological properties of waste edible vegetable oil rejuvenated asphalt binders. Constr. Build. Mater. 2014, 66, 286-298. [CrossRef]

10. Azahar, W.N.A.W.; Jaya, R.P.; Hainin, M.R.; Bujang, M.; Ngadi, N. Chemical modification of waste cooking oil to improve the physical and rheological properties of asphalt binder. Constr. Build. Mater. 2016, 126, 218-226. [CrossRef]

11. Zhang, D.; Chen, M.; Wu, S.; Liu, J.; Amirkhanian, S. Analysis of the Relationships between Waste Cooking Oil Qualities and Rejuvenated Asphalt Properties. Materials 2017, 10, 508. [CrossRef] [PubMed]

12. Bowers, B.F.; Huang, B.; Shu, X.; Miller, B.C. Investigation of Reclaimed Asphalt Pavement blending efficiency through GPC and FTIR. Constr. Build. Mater. 2014, 50, 517-523. [CrossRef]

13. ASTM D2872-12e1. Standard Test Method for Effect of Heat and Air on a Moving Film of Asphalt (Rolling Thin-Film Oven Test); ASTM International: West Conshohocken, PA, USA, 2012.

14. ASTM D6521-13. Standard Practice for Accelerated Aging of Asphalt Binder Using a Pressurized Aging Vessel (PAV); ASTM International: West Conshohocken, PA, USA, 2013.

15. ASTM D92-16b. Standard Test Method for Flash and Fire Points by Cleveland Open Cup Tester; ASTM International: West Conshohocken, PA, USA, 2016.

16. ASTM D5/D5M-13. Standard Test Method for Penetration of Bituminous Materials; ASTM International: West Conshohocken, PA, USA, 2013.

17. ASTM D36/D36M-14e1. Standard Test Method for Softening Point of Bitumen (Ring-and-Ball Apparatus); ASTM International: West Conshohocken, PA, USA, 2014.

18. ASTM D113-17. Standard Test Method for Ductility of Asphalt Materials; ASTM International: West Conshohocken, PA, USA, 2017.

19. ASTM D4402/D4402M-15. Standard Test Method for Viscosity Determination of Asphalt at Elevated Temperatures Using a Rotational Viscometer; ASTM International: West Conshohocken, PA, USA, 2015.

20. D'Angelo, J. The Relationship of the MSCR Test to Rutting. Road Mater. Pavement Des. 2009, 10 (Suppl. 1), 61-80. [CrossRef]

21. D'Angelo, J.; Kluttz, R.; Dongre, R.N.; Stephens, K.; Zanzotto, L. Revision of the Superpave high temperature binder specification: The multiple stress creep recovery test (with discussion). J. Assoc. Asphalt Paving Technol. 2007, 76, 123-162.

22. Bahia, H.U.; Hanson, D.I.; Zeng, M.; Zhai, H.; Khatri, M.A.; Anderson, R.M. Characterization of Modified Asphalt Binders in Superpave Mix Design; The National Academies of Sciences, Engineering, and Medicine: Washington, DC, USA, 2001.

23. Nayak, P.; Sahoo, U.C. Rheological, chemical and thermal investigations on an aged binder rejuvenated with two non-edible oils. Road Mater. Pavement Des. 2017, 18, 612-629. [CrossRef]

24. Fernándezgómez, W.D.; Quintana, H.A.R.; Reyeslizcano, F. A review of asphalt and asphalt mixture aging. Ing. Investig. 2012, 33, 5-12.

(C) 2018 by the authors. Licensee MDPI, Basel, Switzerland. This article is an open access article distributed under the terms and conditions of the Creative Commons Attribution (CC BY) license (http://creativecommons.org/licenses/by/4.0/). 